\title{
Comparison of Dentinal Defects induced by Hand Files, Multiple, and Single Rotary Files: A Stereomicroscopic Study
}

\author{
${ }^{1}$ Atul Jain, ${ }^{2}$ Kanchan Bhadoria, ${ }^{3}$ Bharat Choudhary, ${ }^{4}$ Nakul Patidar
}

\begin{abstract}
Aim: This study was carried out to compare the dentinal defects induced by single rotary file system, multiple rotary file system, and hand files.

Materials and methods: Sixty single-rooted premolars were selected based on predetermined criteria. They were divided into three groups: Group I (hand K files), group II (Hero Shaper), and group III (One Shape). Biomechanical preparation was carried out as per the manufacturer's instructions. Each specimen was sectioned horizontally and divided into apical, middle, and coronal sections. These sections were visualized under stereomicroscope to evaluate the dentinal defects using predetermined criteria.
\end{abstract}

Results: Roots prepared with Hero Shaper showed more number of defects than One Shape, whereas in roots prepared with hand files lowest percentage of dentinal defects were present. There was statistically significant difference between the Hero Shaper group and the One Shape group $(p<0.05)$.

Conclusion: All rotary files induce defects in root dentin, whereas the hand instruments induce minimal defects.

Clinical significance: With single rotary file system, preparation time is reduced and it is easier for patients to accept the treatment. Moreover, the potential of root fracture is reduced.

Keywords: Dentinal defects, Hero Shaper, K files, One Shape.

How to cite this article: Jain A, Bhadoria K, Choudhary B, Patidar N. Comparison of Dentinal Defects induced by Hand Files, Multiple, and Single Rotary Files: A Stereomicroscopic Study. World J Dent 2017;8(1):45-48.

Source of support: Nil

Conflict of interest: None

\section{INTRODUCTION}

Elimination of the microorganism, debris along with tissue from the canal, perfect designing of the canal

\footnotetext{
${ }^{1}$ Professor and Head, ${ }^{2-4}$ Postgraduate Student

${ }^{1-4}$ Department of Conservative Dentistry and Endodontics RKDF Dental College and Research Center, Bhopal, Madhya Pradesh, India

Corresponding Author: Kanchan Bhadoria, Postgraduate Student, Department of Conservative Dentistry and Endodontics RKDF Dental College and Research Center, Bhopal, Madhya Pradesh, India, Phone: +919039490244, e-mail: bhadoria. kanchan@gmail.com
}

diameter, and three-dimensional seal of root canal system are the three major steps for successful endodontic treatment. ${ }^{1}$ Proper and adequate biomechanical preparation is one of the major steps toward achieving this goal. Most of the clinicians prefer rotary NiTi files over stainless steel file because of its rapid canal shaping which is more centered with less chances of canal transportation., ${ }^{2,3}$

Nevertheless, some functions of NiTi rotary systems, such as cleaning ability, increased stress, and the inability to adequately prepare oval canals are still controversial. ${ }^{4}$ However, canal preparation with larger tapered rotary NiTi instruments involves more dentin removal, which compromises the fracture strength of the roots and can induce fractures, either complete or partial. ${ }^{5}$

Relationship between the design of NiTi instruments and the incidence of vertical root fracture has been established. It was found that file design affected apical stress and strain concentrations during root canal instrumentation. ${ }^{6}$

Endodontically treated teeth have a long-term functional survival rate, but they are more prone to fracture when compared to vital teeth. ${ }^{7}$ Recent studies have shown that root fracture is not an instant event but rather gradual propagation of tiny, less pronounced craze lines in tooth structure. ${ }^{8-10}$ Structural defects in a tooth have been shown to influence fracture strength as stress is exponentially amplified at the tips of these cracks.9

In the last decades, many new NiTi rotary instruments have been developed and introduced by various manufacturers. With the development of different rotary systems, the concept of single rotary file system has evolved. A single file system is certainly simple in concept compared to multiple files and sounds like it could be easier to use as well. One Shape is the one of the recently developed single file system with simplicity, safety and efficacy being its unique characteristics. ${ }^{11}$ Studies on the role of One Shape file related to its behavior on root dentin are far and few. Thus, this in vitro study was taken up to compare the dentinal defects induced by One Shape single rotary file system, Hero Shaper multiple rotary file system, and hand files.

\section{MATERIALS AND METHODS}

Freshly extracted permanent mandibular premolars were collected from the outpatient department of oral 
and maxillofacial surgery, RKDF Dental College and Research Centre, Bhopal, India. Teeth were cleaned with ultrasonic scaler for removal of soft tissue, debris, or calculus deposits and stored in distilled water. Premolars were inspected and examined with radiovisiography. Sixty single-rooted premolars, free of defects with single root canal, were selected for this study. Teeth with calcified canals, excessively wide canal, severely curved root, external or internal resorption, developmental anomalies, fractured or crazed root, root with restoration, and previously endodontically treated teeth were excluded.

The teeth were decoronated using a diamond disk, leaving roots approximately $12 \mathrm{~mm}$ in length. Patency of the canal was established using a no. 10 K-File (Mani, Japan) in the canal. After establishing the patency, the specimens were equally divided into three groups.

In group I, canal was prepared with $\mathrm{K}$ files (Mani, Japan) using step back technique apically till \#25 and coronally till \#50. In group II, canals were prepared with Hero Shaper (Micro-Mega, France) till \#25(4\%) using crown down technique. In group III, canals were prepared with One Shape (Micro-Mega, France) till \#25(6\%) using crown down technique. During the biomechanical preparation irrigation was carried out with $5.25 \%$ sodium hypochlorite $(\mathrm{NaOCl})$.

\section{Sectioning and Microscopic Evaluation}

Horizontal sectioning of all the roots was carried out at 9,6 , and $3 \mathrm{~mm}$ using a diamond disk under water cooling. These sections were individually observed under stereomicroscope (Lafco, India) at $\times 40$ magnification, and photographs were taken using a digital camera.

Photographs of each section were evaluated by a person not associated with the study. The dentinal defects were evaluated as - "no defect - root dentin devoid of any lines or cracks, where both the external surface of the root and the internal root canal wall did not present any evident defects," "fracture - a line extending from the root canal space, all the way to the outer surface of the root," and "other defects - a craze line, a line extending from the outer surface into the dentin but will not reach the canal lumen, or a partial crack, a line extending from the canal walls into the dentin without reaching the outer surface."

Results obtained were expressed as number and percentage. Statistical analysis was performed using chi-square test. The level of significance was set $\mathrm{p}=0.05$.

\section{RESULT}

In coronal 3rd, fracture was observed only in group II in one sample. Other defects were again observed only in group II in two samples.
Table 1: Defects in different thirds of the root

\begin{tabular}{llllll}
\hline \multirow{2}{*}{ Section } & & \multicolumn{2}{c}{$\begin{array}{l}\text { Other } \\
\text { Fracture } \\
\text { defects }\end{array}$} & No defects & $\begin{array}{l}\text { Statistical } \\
\text { reference }\end{array}$ \\
\hline Apical & Group I & $1(5 \%)$ & $3(15 \%)$ & $16(80 \%)$ & Chi-square \\
& Group II & 0 & $2(10 \%)$ & $18(90 \%)$ & value: 78.304 \\
& Group III & $1(5 \%)$ & $1(5 \%)$ & $18(90 \%)$ & p-value: 0.001 \\
Middle & Group I & 0 & 0 & $20(100 \%)$ & Chi-square \\
& Group II & $3(15 \%)$ & $4(20 \%)$ & $13(65 \%)$ & value: 14.503 \\
& Group III & $1(5 \%)$ & $3(15 \%)$ & $16(80 \%)$ & p-value: 0.005 \\
Coronal & Group I & 0 & 0 & $20(100 \%)$ & Chi-square \\
& Group II & $1(5 \%)$ & $2(10 \%)$ & $17(85 \%)$ & value: 10.527 \\
& Group III & 0 & 0 & $20(100 \%)$ & p-value: 0.035 \\
\hline
\end{tabular}

In middle 3rd, fracture was observed in three sample in group II and in one sample in group III. Other defects were observed in four samples in group II and in three samples in group III.

In apical 3rd, fracture was observed in one sample in each groups I and III whereas, other defects were observed in three samples in group I, two samples in group II, and one sample in group III. Rest of the samples did not display any defect (Table 1).

\section{DISCUSSION}

During biomechanical preparation, rotational forces applied on the walls of the root canal result in formation of microcracks or craze lines. ${ }^{12}$ According to Dilek et al, ${ }^{13}$ all instruments, including hand instruments, cause dentinal defects. When rotary files are used, the latter are magnified in comparison to hand files. These defects may be caused due to various reasons: Tip design, crosssection geometry, constant or variable taper, and pitch and flute form. In a study, Garima Mohan ${ }^{14}$ found that hand $\mathrm{K}$ and $\mathrm{H}$ files produced less number of defects than rotary NiTi files (Profile, Protaper, RACE, and Hero Shaper).

In our study, use of Hero Shaper files resulted in highest incidence of defects compared to One Shape and hand $\mathrm{K}$ files. The dentinal defect that arises in the root during the canal preparation depend on the taper, design, and rotations per minute (rpm) of the instrument. In Hero Shaper, helical angle of cutting edges varies from tip to the shank and adapted pitch, i.e., pitch varies according to taper, positive rake angle, large inner core, and three edges. ${ }^{15,16}$ They tend to generate greater stress on the root walls and possess relatively low flexibility. Higher stress induction on the walls is due to greater number of rpm, resulting in faster and more aggressive cutting. At the same time, due to positive rake angle and lower contact area as compared to hand files, the stress concentration is higher. Hand files produced least defects because the amount of force application is less, the number of rotation is less, and screwing effect is not present. 
As a supposed evolutionary procedural evolvement of multiple file system (Hero Shapers), single file system (One Shape) are thought to facilitate the biomechanical preparation, consisting of one sterile single file for root canal shaping (ISO 25 tip and 6\% taper) with variable pitch, positive rake angle, and nonworking (safety) tip. It works with continuous rotation. It has increased flexibility and reduced instrument screwing effect due to a variable cross-section along the blade of the instrument. It has three different cross-section zones: Apical (with a variable three-cutting-edge design), transitional (progressively changing from three to two cutting edges), and coronal (with two cutting edges). ${ }^{17,18}$

According to Zandbiglari et $\mathrm{a}^{19}$ greater taper instruments significantly weaken the root. Krishna et $\mathrm{al}^{20}$ also confirmed that when taper of the instrument is increased, it tends to remove more root dentin, compromising the root which is more likely to get dentinal defects. Bier et $\mathrm{al}^{8}$ found that when NiTi rotary instruments with a taper of 0.06 or more are used, dentinal defects result. Contrary to these findings, in our study, One Shape file - although possessing greater taper than the last used Hero Shaper file - did not result in higher number of dentinal defects. The probable reason for this result could be because the number of cutting edges reduced from three to two in apical and coronal region respectively with One Shape. Although the taper is more, the cutting edges remain three throughout the length in case of Hero Shaper.

Hero Shapers produced most defects in the middle 3rd of the canal, followed by coronal, and least in the apical 3rd, whereas $\mathrm{K}$ files produced defects only in the apical 3rd. One Shape produced defects in the apical and middle 3rd only. Hero Shapers possess maximal diameter of blade corresponding to coronal and middle $3 \mathrm{rd}$. The root preparation is started with $6 \%$ taper file, which has greater diameter at coronal and middle 3rd and is reinforced by subsequently used $4 \%$ instruments. They have positive rake angle which further adds to the defect propagation due to greater surface contact.

With hand $\mathrm{K}$ files, defects were found to be present only in the apical 3rd which again is in keeping with the used step back technique. Since the initial filling is in the apical 3rd, it tends to induce maximal stress, and once the preparation is taken to the middle and coronal $3 \mathrm{rd}$, the stress concentration decreases in the coronal direction. The initial limited canal width further leads to the defect initiation and propagation.

Reduction in dentin wall thickness is an important factor for increased fracture susceptibility. ${ }^{21}$ Mostly, fractures were located in apical and mid-root area, due to higher load located under cementoenamel junction. Contrary to our study, Milani et $\mathrm{al}^{9}$ found that hand $\mathrm{K}$ files produced more number of defects than rotary files. In their study, they used large tapered rotary files in mandibular incisors; however, by including periodontal ligament simulation, the relative number of defects in the rotary group was low and the difference was not significant.

Dhingra et $\mathrm{al}^{22}$ and Lui et $\mathrm{al}^{23}$ in separate studies, found that One Shape caused more number of defects than other single rotary file system (WaveOne, Reciproc, and self-adjusting file ). The probable reason as stated in their study was that the reciprocating movement minimizes torsional and flexural stresses and reduces canal transportation. ${ }^{22-25}$

\section{CONCLUSION}

Within the limitation of the study it can be concluded that all the instruments, including hand $\mathrm{K}$ file, induced dentinal defects, but this is less in comparison to the rotary files. Among rotary file system, single file system induced less number of defects when compared to multiple file system. However, for more conclusive result, a more elaborated study needs to be carried out.

\section{CLINICAL SIGNIFICANCE}

Single file rotary systems - owing to ease of learning and use, faster canal preparation, with reduced risk of crossinfection, being economical as well as resulting in lesser number of defects in the dentin - have the potential to become the preferred rotary instruments.

\section{REFERENCES}

1. Çiçek E, Koçak MM, Sa lam BC, Koçak S. Evaluation of micro crack formation in root canals after instrumentation with different NiTi rotary file systems: a scanning electron microscopy study. Scanning 2015 Jan-Feb;37(1):49-53.

2. Yoldas O, Yilmaz S, Atakan G, Kuden C, Kasan Z. Dentinal microcrack formation during root canal preparations by different NiTi rotary instruments and the self-adjusting file. J Endod 2012 Feb;38(2):232-235.

3. Liu ZX, Liu Y, Ww Chang J, Yuan CY, Zhang CF, Wang PL. Morphological analysis of apical foramen over-instrumented by three rotary NiTi systems. Chin J Dent Res 2014;17(2): 111-116.

4. Rahman H, Chandra A, Singh S. In vitro evaluation of dentinal Microcrack formation during root canal preparations by different NiTi systems. IJRD 2014;3(2):43-47.

5. Jindal N, Khetan R, Kumar Y, Aggarwal R, Aggarwal K. The incidence of dentinal microcracks caused by hand versus different rotary instruments after biomechanical preparation: an in vitro study. World J Pharama Life Sci 2016;2(2):145-153.

6. Kim HC, Lee MH, Yum J, Versluis A, Lee CJ, Kim BM. Potential relationship between design of nickel-titanium rotary instruments and vertical root fracture. J Endod 2010 Jul;36(7):1195-1199.

7. Tang $\mathrm{W}, \mathrm{Wu} \mathrm{Y}$, Smales RJ. Identifying and reducing risks for potential fractures in endodontically treated teeth. J Endod 2010 Apr;36(4):609-617. 
8. Bier CA, Shemesh H, Tanomaru-Filho M, Wesselink PR, Wu MK. The ability of different nickel-titanium rotary instruments to induce dentinal damage during canal preparation. J Endod 2009 Feb;35(2):236-238.

9. Milani AS, Froughreyhani M, Rahimi S, Jafarabadi MA, Paksefat $\mathrm{S}$. The effect of root canal preparation on the development of dentin cracks. Iran Endod J 2012 Oct;7(4):177-182.

10. Rippe MP, Santini MF, Bier CA, Baldissara P, Valandro LF. Effect of root canal preparation, type of endodontic post and mechanical cycling on root fracture strength. J Appl Oral Sci 2014 Jun;22(3):165-173.

11. Dhingra A, Ruhal N, Bhardwaj N, Rohilla S. Single file systems: a review. Int J Sci Stud 2015;2(11):169-172.

12. De-Deus G, Belladonna FG, Souza EM, Silva EJ, de Almeida Neves A, Alves H, Lopes RT, Versiani MA. Micro-computed tomographic assessment on the effect of protaper next and twisted file adaptive systems on dentinal cracks. J Endod 2015 Jul;41(7):1116-1119.

13. Helvacioglu-Yigit D, Aydemir S, Yilmaz A. Evaluation of dentinal defect formation after root canal preparation with two reciprocating systems and hand instruments: an in vitro study. Biotechnol Biotechnol Equip 2015 Mar;29(2):368-373.

14. Mohan G. A comparative evaluation of effect of instrument design on inducing root fracture - an in-vitro study. Arch Dent Med Res 2015;1(2):1-13.

15. Yang GB, Zhou XD, Zheng YL, Zhang H, Shu Y, Wu HK. Shaping ability of progressive versus constant taper instruments in curved root canals of extracted teeth. Int Endod J 2007 Sep;40(9):707-714.

16. Veltri M, Mollo A, Mantovani L, Pini P, Balleri P, Grandini S. A comparative study of endoflare - Hero Shaper and Mtwo NiTi instruments in the preparation of curved root canals. Int Endod J 2005 Sep;38(9):610-616.

17. Karova ST. WaveOne and One Shape files: survival in severely curved artificial canals. Global J Med Res 2014 Aug;14(4).
18. Tambe VH, Nagmode PS, Abraham S, Patait M, Lahoti PV, Jaju N. Comparison of canal transportation and centering ability of rotary ProTaper, One Shape system and WaveOne system using cone beam computed tomography: an in vitro study. J Conserv Dent 2014 Nov;17(6):561-565.

19. Zandbiglari $T$, Davids $H$, Schäfer E. Influence of instrument taper on the resistance to fracture of endodontically treated roots. Oral Surg Oral Med Oral Pathol Oral Radiol Endod 2006 Jan;101(1):126-131.

20. Krishna. NV, Kumar CS, Madhusudhana K, Mathew VB, Reddy ECA, Babu TL. Evaluation of dentinal damage after root canal preparation with protaper universal, twisted files and Mtwo rotary systems - an in vitro study. Int J Med Appl Sci 2014;3(4):146-151.

21. Sathorn C, Palamara JE, Messer HH. A comparison of the effects of two canal preparation techniques on root fracture susceptibility and fracture pattern. J Endod 2005 Apr;31(4): 283-287.

22. Dhingra A, Saurabh D, Bhullar HK. To compare and evaluate the microcracks caused by 3 different single file systems versus the ProTaper next. Guident 2014 Sep;7(10).

23. Liu R, Hou BX, Wesselink PR, Wu MK, Shemesh H. The incidence of root microcracks caused by 3 different singlefile systems versus the ProTaper system. J Endod 2013 Aug;39(8):1054-1056.

24. Priya NT, Chandrasekhar VE, Anita S, Tummala MU, Raj TB, Badami VI, Kumar PR, Soujanya E. "Dentinal microcracks after root canal preparation" a comparative evaluation with hand, rotary and reciprocating instrumentation. J Clin Diagn Res 2014 Dec;8(12):ZC70-2.

25. Gergi RM, Osta NE, Naaman AS. Dentinal crack formation during root canal preparations by the twisted file adaptive, Reciproc and WaveOne instruments. Eur J Dent 2015 OctDec;9(4):508-512. 